\title{
ПРИКЛАДНАЯ ЭКОНОМИКА
}

УДК 338.48

Е.Ф. Гонтарева, магистрант, Д.А. Рубан, $\mathrm{PhD}$, канд. геол.-минерал. наук, доцент, ${ }^{1}$ г. Ростов-на-Дону, Россия

\section{РАЗВИТИЕ ГОСТИНИЧНОГО ХОЗЯЙСТВА В РОССИИ: ПРОСТРАНСТВЕННАЯ ДИНАМИКА ОСНОВНЫХ ПАРАМЕТРОВ}

Развитие внутреннего туризма является исключительно актуальной задачей для России, равно как и увеличение числа прибытий иностранных туристов. Для успешного решения требуется наличие хорошо развитой инфраструктуры. Ситуация в российской индустрии туризма и гостеприимства известна, однако разработка комплексных моделей, позволяющих описывать характер развития гостиничного хозяйства, сохраняет свою актуальность. Целью настоящего исследования является изучение пространственной динамики основных параметров развития гостиничного хозяйства России. Работа основана на количественном анализе статистических данных за 2009-2014 гг. Изучаются три основных параметра: число лиц, размещенных в коллективных средствах размещения (КСР), число мест в КСР и объем платных услуг, оказанных КСР. В основе расчета показателей пространственной динамики этих параметров лежит определение показателя парной корреляции. Результаты расчетов показывают, что пространственная динамика всех основных параметров развития гостиничного хозяйства России характеризуется низкой интенсивностью. Это означает, что соотношение территорий по параметрам этого хозяйства остается почти неизменным. Динамика числа лиц, размещенных в КСР, и числа мест в КСР характеризуются сравнимо низкими значениями соответствующих показателей. Однако пространственные изменения, касающиеся такого параметра как объем платных услуг, оказанных КСР, оказываются несколько большими. Сравнительно высокой интенсивностью пространственная динамика отличалась в Сибирском федеральном округе. Дальнейший анализ полученных результатов позволяет установить, что обнаруживает достаточно слабую связь между отдельными параметрами. Факторы пространственной динамики основных параметров развития гостиничного хозяйства в России могут быть различными. К ним относится, в частности, влияние экономических процессов в регионах. Спортивные и прочие крупные международные мероприятия, которые потребовали трансформации гостиничного хозяйства, не оказали заметного влияния на изученную динамику. Сделан общий вывод о том, что распределение изученных параметров по регионам мало менялось в 2009-2014 гг., что свидетельствует о недостаточной конкурентоспособности многих регионов в отношении их гостиничного хозяйства.

Ключевые слова: коллективные средства размещения; корреляционный анализ; пространственные закономерности; региональная экономика; туризм.

\section{Введение}

Развитие внутреннего туризма является исключительно актуальной задачей для России, обсуждение чего ведется как в профессиональном сообществе, так и в научных кругах. С одной стороны, ее решение необходимо для предоставления возможности полноценного отдыха всем гражданам страны, а с другой - для повышения экономической эффективности индустрии туризма и гостеприимства за счет снижения транзакционных издержек, неизбежных при ориентации на выездной туризм, равно как и ее участия в решении социальных про-

\footnotetext{
1 Гонтарева Елена Федотовна - магистрант Высшей школы бизнеса Южного федерального университета, г. Ростов-на-Дону, Россия (344019, г. Ростов-на-Дону, ул. 23-я линия, 43); e-mail: lenagontareva@bk.ru.
} 
блем путем создания новых рабочих мест и т. д. Второй задачей, тесно связанной с первой, является увеличение числа прибытий в Россию иностранных туристов, что обеспечивает дополнительные доходы (прямые и косвенные) как самих организаций сферы туризма, так и федерального и региональных бюджетов. Несмотря на то, что мировой рынок туристических ${ }^{2}$ услуг уже хорошо сформирован [1], Россия обладает достаточным потенциалом для того, чтобы упрочить на нем свои позиции за счет роста въездного потока и диверсификации предлагаемых услуг. При этом стоит учитывать, какое влияние глобальные процессы в экономике [2] оказывают на развитие индустрии туризма и гостеприимства [3].

Вполне очевидно, что решение обеих вышеуказанных задач возможно только в случае высокого качества предоставляемых туристических услуг, что, в свою очередь, означает наличие хорошо развитой инфраструктуры, и прежде всего гостиничного хозяйства. Действительно, именно количество коллективных средств размещения (КСР), к каковым относятся прежде всего гостиницы, их состояние и качество обслуживания способствуют как развитию внутреннего туризма, так и посещению страны иностранными

Рубан Дмитрий Александрович - Philosophiae Doctor, кандидат геолого-минералогических наук, доцент Высшей школы бизнеса Южного федерального университета, г. Ростов-на-Дону, Россия (344019, г. Ростов-наДону, ул. 23-я линия, 43); e-mail: ruban-d@mail.ru.

2 Авторы используют прилагательные «туристский» и «туристический», следуя сложившейся в мировой науке (и российской науке как ее составляющей) и практике (например, «туристский поток», но «туристическая индустрия», в англоязычной терминологии «tourist flow», но «tourism industry») нормам русского языка и с учетом очевидных смысловых различий. При этом авторы не желают вступать в настоящей статье в дискуссию относительно приемлемости термина «туристический», активно ведущуюся в отечественном профессиональном сообществе и, безусловно, признают прилагательное «туристский» в качестве единственно юридически закрепленного. туристами. Например, становление новых финансовых центров в нашей стране [4] означает рост делового туризма. Более того, последний сам по себе может способствовать экономическому развитию регионов, т. к. выступает важным средством обмена знаниями и опытом. Однако это означает также необходимость размещения сравнительно большого числа туристов (руководителей и официальных представителей предприятий и организаций), требования которых к качеству гостиничных услуг по определению высоки. В целом для того чтобы планировать комплекс мероприятий по решению двух обозначенных задач, необходимо иметь детальные представления о характере развития гостиничного хозяйства России за последние годы.

Ситуация в российской индустрии туризма и гостеприимства охарактеризована в большом числе работ (например, [5-7]). Возможности управления этой индустрией также хорошо известны [8-14]. Ряд исследователей совершенно справедливо акцентируют внимание на изучении туристских потоков [15-18], величина которых влияет в отдельных случаях на конкурентоспособность территорий [18]. Воздействие разнообразных факторов на состояние гостиничного хозяйства в регионах устанавливается современными методиками $[19,20]$. Вполне логично, что исследователи уделяют должное внимание международным группам отелей (т. н. цепочкам) $[7,21,22]$ и кластерам $[23,24]$, т. к. они играют все большую роль в развитии индустрии туризма и гостеприимства в регионах. Тем не менее разработка комплексных моделей, позволяющих описывать характер развития гостиничного хозяйства, ведется недостаточно активно и, следовательно, сохраняет свою актуальность. Более того, огромная площадь, занимаемая Россией, усложняет эту задачу, т. к. в применении к нашей стране подобного рода модели обязательно должны учиты- 
вать не только временную, но и пространственную составляющую развития.

Целью настоящей работы является количественный анализ пространственной динамики основных параметров развития гостиничного хозяйства России. Полученные результаты позволяют охарактеризовать изменение состояния этого хозяйства по регионам за последние годы и сделать ряд практических выводов. Насколько известно авторам, подобного рода анализ проводится для России впервые.

\section{Материалы и методы}

Статистические исследования играют важную роль при изучении состояния и развития индустрии туризма и гостеприимства [25-30]. Настоящая работа основана на количественном анализе данных, предоставляемых в режиме свободного доступа Федеральным агентством по туризму. Изучаются три основных параметра, характеризующих развитие гостиничного хозяйства (табл. 1). Параметр ТН отражает востребованность КСР и с некоторыми допущениями может интерпретироваться как показатель величины туристского потока. Допущения связаны с невозможностью учесть, во-первых, туристов, которые не пользуются услугами КСР, а во-вторых, совершающих в той или иной мере краткосрочные поездки на личном транспорте (развитие автомобильного туризма [31], несомненно, может повлиять на размещение в КСР). Кроме того, не все лица, воспользовавшиеся услугами КСР, являются туристами в строгом смысле. Параметр РН показывает число имеющихся в наличии мест для размещения туристов, т. е. размер номерного фонда или в более общем виде потенциал КСР. Наконец, параметр ІН является наиболее простой, но существенной для настоящего анализа экономической характеристикой гостиничного хозяйства, т. к. отражает результативность деятельности КСР в денежном выражении.
На первый взгляд, перечисленные параметры достаточно сходны и в идеальном случае напрямую связаны друг с другом. Однако в действительности связь между ними может оказаться значительно меньше, что также служит предметом настоящего изучения. Так, вовсе не все имеющиеся в наличии места для размещения туристов могут оказаться заполненными. Например, в Тульской области в 2012 г. имело место незначительное сокращение числа лиц, воспользовавшихся КСР, тогда как число гостиниц и, следовательно, номерной фонд, увеличились [32]. Следовательно, имеющийся потенциал размещения использовался не полностью. Что касается объема платных услуг, то он может возрастать при неизменном туристском потоке в том случае, если туристы массово отдают предпочтение проживанию в более дорогих номерах, или снижаться, если они, напротив, стали предпочитать более дешевое размещение. Более того, на денежное выражение деятельности КСР оказывает влияние инфляция и прочие факторы. В этой связи три вышеотмеченных параметра должны анализироваться раздельно.

Методика проводимого анализа состоит в следующем. Для оценки пространственной динамики основных параметров развития гостиничного хозяйства России необходимо использовать некоторый показатель, который бы характеризовал изменения в распределении ТН, $\mathrm{PH}$ и IH по регионам с течением времени. В этих целях может быть использован тот же подход, что и при анализе инновационной среды как предпосылки развития туризма [33]. Коэффициент парной корреляции [34], который используется для решения различных эконометрических задач [35], характеризует сходство двух выборок значений. Взяв информацию о значениях конкретного параметра в каждом субъекте Федерации за два последовательных года (например, 2011 и 2012 г.), можно рассчитать корреляцию выборок этих значе- 
ний по стандартной методике [34, 35]. Полученная в итоге цифра будет характеризовать степень сходства в пространственном распределении значений данного показателя. Так как коэффициент парной корреляции изменяется в пределах от - 1 до +1 , то, вычитая его значение из 1 , получаем некоторую меру уже не сходства, а различия в распределении значений анализируемого параметра. Чем больше будет значение такого показателя, тем большими были изменения параметра в пространстве страны. Например, если анализируется параметр $\mathrm{IH}$, то речь идет о пространственных изменениях в объеме платных услуг, оказанных КСР. Эти изменения проявляются в том, что в один год их объем был сравнительно большим в одних регионах, а в следующий год - в других.

В настоящей работе используются три показателя, рассчитываемые по приводимым ниже формулам:

$$
\text { Dth }=1-\text { Rth, }
$$

где Dth - показатель пространственной динамики числа лиц (туристов), размещенных в КСР, Rth - коэффициент корреляции значений ТН в регионах за два года;

$$
D p h=1-R p h,
$$

где $D p h$ - показатель пространственной динамики мест в КСР, $R p h$ - коэффициент корреляции значений РН в регионах за два года;

$$
\operatorname{Dih}=1-\text { Rih },
$$

где $D i h$ - показатель пространственной динамики объема платных услуг, оказанных КСР, Rih - коэффициент корреляции значений IН в регионах за два года.

Так как значения Rth, Rph и Rih изменяются от -1 до +1 , то значения Dth, Dph и Dih изменяются от 0 до +2 . Чем выше значение, тем более интенсивной была динамика, тем, следовательно, большими были изменения в распределении значения параметра по регионам.

Статистические данные Ростуризма позволяют провести расчет показателей пространственной динамики для России в целом с корреляцией значений для федеральных округов, для России в целом с корреляцией значений для регионов, а также для всех федеральных округов (кроме Крымского, для которого по объективным причинам отсутствуют данные) с корреляцией значений для регионов. С учетом имеющихся статистических данных значения показателей пространственной динамики можно определить для каждой пары последовательных лет на интервале с 2009 по 2014 г. (табл. 1). Вполне очевидно, что изменения от года к году будут весьма небольшими, т. к. трудно ожидать одновременного ввода в строй или, наоборот, закрытия действительно большого числа гостиниц в каком-нибудь отдельном регионе. В этой связи небольшие цифры не являются следствием низкой чувствительности используемого метода, а характеризуют действительное развитие гостиничного хозяйства в абсолютном выражении. Тем не менее имеет смысл проанализировать изменения в долговременной перспективе. В этих целях $D t h, D p h$ и $D i h$ рассчитываются также для двух годов, соответствующих началу и концу анализируемого временного интервала, т. е. 2009 г. и 2014 г. (далее такое сравнение непоследовательных во времени выборок значений обозначается как «2009 v 2014»).

\section{Результаты}

Пространственная динамика числа лиц, размещенных в КСР, характеризуется весьма небольшими значениями (табл. 2). В России в целом она несколько выросла только ближе к концу рассматриваемого временного интервала, что свидетельствует о небольшом смещении туристских потоков с одних территорий на другие. Чуть большие значения показателя Dth, устанавливаемые при анализе развития по регионам, чем по округам, говорят об ограниченном характе- 
ре этих изменений. Из федеральных округов наиболее интенсивная динамика характерна для Сибирского и Уральского, тогда как наименьшая - для Южного и СевероКавказского (также малая интенсивность динамики отмечается в Северо-Западном и Центральном округах). Наибольшие изменения в распределении числа лиц, размещенных в КСР, по регионам происходили в разных округах в разные годы; ни в одном округе не удается выявить четко выраженных тенденций, которые были бы связаны с усилением или снижением пространственной динамики. Можно говорить лишь о кратковременных интенсификациях, наподобие той, что имела место в Уральском федеральном округе в 2010-2011 гг.

В долгосрочной перспективе пространственная динамика числа лиц, размещенных в КСР, также характеризуется малой интенсивностью, что характерно как для страны в целом, так и для отдельных федеральных округов (табл. 2). Однако стоит обратить особое внимание на Сибирский, Уральский и Приволжский округа, где интенсивность этой динамики была сравнительно высокой. Следовательно, на этих территориях с течением времени происходило несколько большее смещение туристских потоков из одних регионов в другие.

Пространственная динамика числа мест в КСР также характеризуется весьма небольшими значениями (табл. 3). В России в целом она слегка выросла только ближе к концу рассматриваемого временного интервала, что свидетельствует о небольшом «перераспределении» номерного фонда между территориями. Значения показателя $D p h$, устанавливаемые при анализе развития по регионам, примерно такие же, как и по округам, что говорит о существенности вышеотмеченных изменений. Из федеральных округов наиболее интенсивная динамика характерна для Сибирского, тогда как наименьшая - для Южного. Наибольшие изменения в распределении числа мест в

Таблица 1

Исходные данные для настоящего анализа*

\begin{tabular}{|c|c|c|c|c|}
\hline $\begin{array}{l}\text { Изучаемый пара- } \\
\text { метр }\end{array}$ & $\begin{array}{l}\text { Единица из- } \\
\text { мерения }\end{array}$ & Источник & $\begin{array}{l}\text { Временной ин- } \\
\text { тервал, для ко- } \\
\text { торого доступны } \\
\text { данные, годы }\end{array}$ & $\begin{array}{l}\text { В о з м о ж н о с т ь } \\
\text { анализа долго- } \\
\text { временных из- } \\
\text { менений (2009 v } \\
2014)\end{array}$ \\
\hline $\begin{array}{l}\text { ТН - число лиц } \\
\text { (туристов), раз- } \\
\text { мещенных в КСР } \\
\text { (суммарно россий- } \\
\text { ских и иностран- } \\
\text { ных граждан) }\end{array}$ & $\begin{array}{l}\text { тысяч чело- } \\
\text { век в год }\end{array}$ & \multirow[t]{3}{*}{$\begin{array}{l}\text { Федераль- } \\
\text { ное агент- } \\
\text { ство по } \\
\text { ту р и з м у } \\
\text { (Р о с т у - } \\
\text { ризм) }\end{array}$} & 2009-2014 & Да \\
\hline $\begin{array}{l}\text { РН - число мест в } \\
\text { КСР }\end{array}$ & $\begin{array}{l}\text { тысяч единиц } \\
\text { по состоянию } \\
\text { на данный } \\
\text { год }\end{array}$ & & 2009-2014 & Да \\
\hline $\begin{array}{l}\text { IH - объем плат- } \\
\text { ных услуг, оказан- } \\
\text { ных КСР }\end{array}$ & $\begin{array}{l}\text { м и л л и о н о в } \\
\text { рублей в год }\end{array}$ & & 2009-2014 & Да \\
\hline
\end{tabular}

Примечание: * составлено авторами. 
КСР по регионам происходили в разных округах в разные годы; ни в одном округе не удается выявить четко выраженных тенденций, которые были бы связаны с усилением или снижением пространственной динамики. Можно говорить лишь о кратковременных интенсификациях, наподобие той, что имела место в Сибирском федеральном округе в 2010-2011 гг. Однако стоит обратить внимание на рост (подчас весьма значительный) интенсивности динамики в 2013-2014 гг., который был особенно существенным в Северо-Западном и Сибирском федеральных округах, но также проявился в Дальневосточном, Приволжском и Северо-Кавказском округах. Как говорилось

Таблица 2

Пространственная динамика числа лиц (туристов), размещенных в КСР (значения Dth рассчитаны авторами по данным Ростуризма (см. табл. 1)) ${ }^{3}$

\begin{tabular}{|c|c|c|c|c|c|c|c|c|}
\hline \multirow{2}{*}{$\begin{array}{c}\text { Анализируемая } \\
\text { территория }\end{array}$} & \multicolumn{8}{|c|}{ Годы } \\
\hline & 2009 & 2010 & \multicolumn{2}{|c|}{2011} & 2012 & 201 & 2014 & $\begin{array}{c}2009 \mathrm{v} \\
2014\end{array}$ \\
\hline $\begin{array}{l}\text { РФ в целом } \\
\text { (округа) }\end{array}$ & 0,003 & \multicolumn{2}{|c|}{0,001} & \multicolumn{2}{|c|}{0,002} & 0,001 & 0,012 & 0,002 \\
\hline $\begin{array}{l}\text { РФ в целом (реги- } \\
\text { оны) }\end{array}$ & 0,005 & \multicolumn{2}{|c|}{0,003} & \multicolumn{2}{|c|}{0,003} & 0,003 & 0,018 & 0,006 \\
\hline $\begin{array}{l}\text { Дальневосточ- } \\
\text { ный федераль- } \\
\text { ный округ }\end{array}$ & 0,002 & \multicolumn{2}{|c|}{0,005} & \multicolumn{2}{|c|}{0,001} & 0,004 & 0,001 & 0,007 \\
\hline $\begin{array}{l}\text { Приволжский фе- } \\
\text { деральный округ }\end{array}$ & 0,006 & \multicolumn{2}{|c|}{0,004} & \multicolumn{2}{|c|}{0,018} & 0,005 & 0,005 & 0,018 \\
\hline $\begin{array}{l}\text { Северо-Западный } \\
\text { ф е д е р а л ь н ы й } \\
\text { округ }\end{array}$ & 0,001 & \multicolumn{2}{|c|}{0,001} & \multicolumn{2}{|c|}{0,002} & 0,001 & 0,001 & 0,009 \\
\hline $\begin{array}{l}\text { Северо-Кавказ- } \\
\text { ский федераль- } \\
\text { ный округ }\end{array}$ & 0,005 & \multicolumn{2}{|c|}{0,000} & \multicolumn{2}{|c|}{0,001} & 0,001 & 0,000 & 0,011 \\
\hline $\begin{array}{l}\text { Сибирский феде- } \\
\text { ральный округ }\end{array}$ & 0,007 & \multicolumn{2}{|c|}{0,009} & \multicolumn{2}{|c|}{0,010} & 0,022 & 0,007 & 0,039 \\
\hline $\begin{array}{l}\text { Уральский феде- } \\
\text { ральный округ }\end{array}$ & 0,002 & \multicolumn{2}{|c|}{0,034} & \multicolumn{2}{|c|}{0,004} & 0,003 & 0,006 & 0,025 \\
\hline $\begin{array}{l}\text { Центральный фе- } \\
\text { деральный округ }\end{array}$ & 0,001 & \multicolumn{2}{|c|}{0,001} & \multicolumn{2}{|c|}{0,000} & 0,002 & 0,001 & 0,002 \\
\hline $\begin{array}{l}\text { Южный } \quad \text { феде- } \\
\text { ральный округ }\end{array}$ & 0,000 & \multicolumn{2}{|c|}{0,000} & \multicolumn{2}{|c|}{0,000} & 0,000 & 0,004 & 0,002 \\
\hline
\end{tabular}

\footnotetext{
${ }^{3}$ В табл. 2-4 информация представлена в форме «смещенных колонок». Это позволяет увидеть соответствие полученных значений именно парам последовательных годов. Использование «традиционной» матричной формы представляется менее
}

уместным, т. к. затрудняет понимание и последующую интерпретацию значений. Авторы надеются, что использованный ими прием отображения числовых результатов найдет должное понимание у читателей. 
выше, аналогичное явление установлено и для России в целом. Все это позволяет утверждать, что потенциал гостиничного хозяйства в последние годы испытал своего рода перестройку в масштабе страны: сделанные выше наблюдения могут быть объяснены только быстрым строительством КСР или, наоборот, их ликвидацией в отдельных регионах и при этом в разных частях страны.

В долгосрочной перспективе пространственная динамика числа мест в КСР также характеризуется малой интенсивностью, что характерно как для страны в целом, так и для отдельных федеральных округов (табл. 3). Однако стоит обратить особое внимание на Сибирский, Северо-Западный, а также Приволжский и Дальневосточный округа, где интенсивность этой динамики была сравнительно высокой. Следовательно, на этих территориях с течением времени номерной фонд изменялся неравномерно; вероятно, он рос в тех регионах, где изначально был сравнительно небольшим. Из перечисленных четырех округов лишь в Дальневосточном эти изменения носили более или менее постепенный характер, т. е. проявлялись на протяжении всего проанализированного временного интервала. 'В остальных округах они стали результатом, главным образом, интенсификации динамики в 2013-2014 г.г.

Пространственная динамика числа мест в КСР

Таблица 3 (значения Dph рассчитаны авторами по данным Ростуризма (см. табл. 1))

\begin{tabular}{|c|c|c|c|c|c|c|c|}
\hline \multirow[b]{2}{*}{$\begin{array}{c}\text { Анализируемая тер- } \\
\text { ритория }\end{array}$} & \multicolumn{7}{|c|}{ Годы } \\
\hline & 2009 & 2010 & 2011 & 2012 & 2013 & 2014 & $\begin{array}{l}2009 v \\
2014\end{array}$ \\
\hline $\begin{array}{l}\text { РФ в целом } \\
\text { (округа) }\end{array}$ & 0,001 & 0,002 & 0,000 & 0,001 & & 0,006 & 0,005 \\
\hline $\begin{array}{l}\text { РФ в целом } \\
\text { (регионы) }\end{array}$ & 0,001 & 0,002 & 0,001 & 0,001 & & 0,006 & 0,004 \\
\hline $\begin{array}{l}\text { Дальневосточный } \\
\text { федеральный округ }\end{array}$ & 0,005 & 0,004 & 0,002 & 0,001 & & 0,009 & 0,025 \\
\hline $\begin{array}{l}\text { Приволжский } \\
\text { федеральный округ }\end{array}$ & 0,008 & 0,018 & 0,007 & 0,004 & & 0,030 & 0,032 \\
\hline $\begin{array}{l}\text { Северо-Западный } \\
\text { федеральный округ }\end{array}$ & 0,003 & 0,001 & 0,003 & 0,004 & & 0,070 & 0,053 \\
\hline $\begin{array}{l}\text { Северо-Кавказский } \\
\text { федеральный округ }\end{array}$ & 0,002 & 0,001 & 0,001 & 0,001 & & 0,005 & 0,004 \\
\hline $\begin{array}{l}\text { Сибирский } \\
\text { федеральный округ }\end{array}$ & 0,016 & 0,029 & 0,018 & 0,002 & & 0,061 & 0,067 \\
\hline $\begin{array}{l}\text { Уральский } \\
\text { федеральный округ }\end{array}$ & 0,015 & 0,000 & 0,003 & 0,003 & & 0,003 & 0,008 \\
\hline $\begin{array}{l}\text { Центральный } \\
\text { федеральный округ }\end{array}$ & 0,001 & 0,001 & 0,002 & 0,003 & & 0,002 & 0,015 \\
\hline $\begin{array}{l}\text { Южный } \\
\text { федеральный округ }\end{array}$ & 0,000 & 0,000 & 0,000 & 0,000 & & 0,000 & 0,000 \\
\hline
\end{tabular}


Пространственная динамика объема платных услуг, оказанных КСР, характеризуется низкими значениями (табл. 4), однако чуть большими в сравнении с другими параметрами (табл. 2, 3). В России в целом она несколько выросла в 2012-2013 гг., что свидетельствует о приобретении отдельными территориями большей результативности оказания КСР платных услуг, чем другими. Значения показателя Dih, устанавливаемые при анализе развития по регионам, примерно такие же, как и по округам, что говорит о существенности этих изменений. Из федеральных округов наиболее интенсивная динамика характерна для Сибирского, Северо-Кавказского и Уральского, тогда как наименьшие (нулевые) значения установлены для Северо-Западного, Центрального и Южного округов. Как и в случае с другими параметрами, наибольшие изменения в распределении числа лиц, размещенных в КСР, по регионам происходили в разных округах в разные годы; ни в одном округе не удается выявить четко выраженных тенденций, которые были бы связаны с усилением или снижением пространственной динамики. Можно говорить лишь о кратковременных интенсификациях, наподобие той, что имела место в Северо-Кавказском федеральном округе в 2012-2013 гг.

В долгосрочной перспективе пространственная динамика объема платных услуг, оказанных КСР, также характеризуется малой интенсивностью, что характерно как для страны в целом, так и для отдельных федеральных округов (табл. 4). Тем не менее значения Dih для 2009 v 2014 в целом выше, чем Dth и $D p h$ (табл. 2,3 ). Более того, в двух федеральных округах (Северо-Кавказском и Дальневосточном) установленные значения превышают 0,1 , а в Сибирском и Приволжском округах они также достаточно велики, т. е. на этих территориях интенсивность пространственной динамики была сравнительно высокой. Это означает, что результативность деятельности гостиничного хозяйства смещалась по регионам в пространстве отмеченных округов. Имеющиеся данные (табл. 4) позволяют утверждать, что эти процессы носили долговременный характер, т. к. для отмеченных четырех округов они прослеживаются на протяжении всего проанализированного временного интервала.

\section{Обобщение и интерпретация резуль-} татов

Результаты предпринятого анализа могут быть суммированы и истолкованы следующим образом. При этом обязательно учитывается, что, согласно данным Ростуризма, ТН, РН и IH направленно росли лишь в отдельных регионах на протяжении анализируемого временного интервала (табл. 5), хотя там, где этого не происходило, спады, как правило, были умеренными и/или достаточно кратковременными.

Анализируя полученные результаты, можно сделать ряд небезынтересных заключений. Во-первых, пространственная динамика всех основных параметров развития гостиничного хозяйства России характеризуется в целом низкой интенсивностью. Это означает, что соотношение территорий по состоянию этого хозяйства оставалось почти неизменным. В тех регионах, где число туристов и мест в КСР, а также объем платных услуг были относительно высоки в 2009 г., они были также относительно высоки и спустя 5 лет, что, необходимо признать, является достаточным сроком для существенных преобразований и, следовательно, ожидаемых изменений. С практической точки зрения, сделанное заключение может интерпретироваться двояко. С одной стороны, очевидна недостаточная конкурентоспособность субъектов Федерации в отношении их туристической инфраструктуры. Реализация крупных проектов в конкретных регионах (особенно отстающих в отношении туристической ин- 
фраструктуры) в таких условиях столкнется с рядом трудностей, а именно с необходимостью либо подчинения инерционным процессам, либо приложения усилий для преодоления отмеченной инерционности. С другой стороны, отсутствие заметных изменений состояния гостиничного хозяйства в пространстве страны есть показатель стабильности. Несомненно, это благоприятная предпосылка для становления в стране индустрии туризма и гостеприимства, и в частности для инвестирования в соответствующие проекты. Нельзя исключать, что низкая интенсивность пространственной динамики является следствием недостаточного быстрого прироста суммарного туристического потока регионов
России. Кроме того, отдельного изучения заслуживает компетентность управленческого персонала КСР, от которой зависят как состояние гостиничного хозяйства, так и его способность к изменению, росту, качественной трансформации.

Во-вторых, интенсивность пространственной динамики основных параметров гостиничного хозяйства возросла ближе к концу проанализированного временного интервала. Это означает некоторое оживление конкуренции регионов и, следовательно, переход к иной модели развития гостиничного хозяйства страны, предполагающей изменение сложившихся пропорций в его распределении по ее территории.

Таблица 4

Пространственная динамика объема платных услуг, оказанных КСР (значения Dih рассчитаны авторами по данным Ростуризма (см. табл. 1))

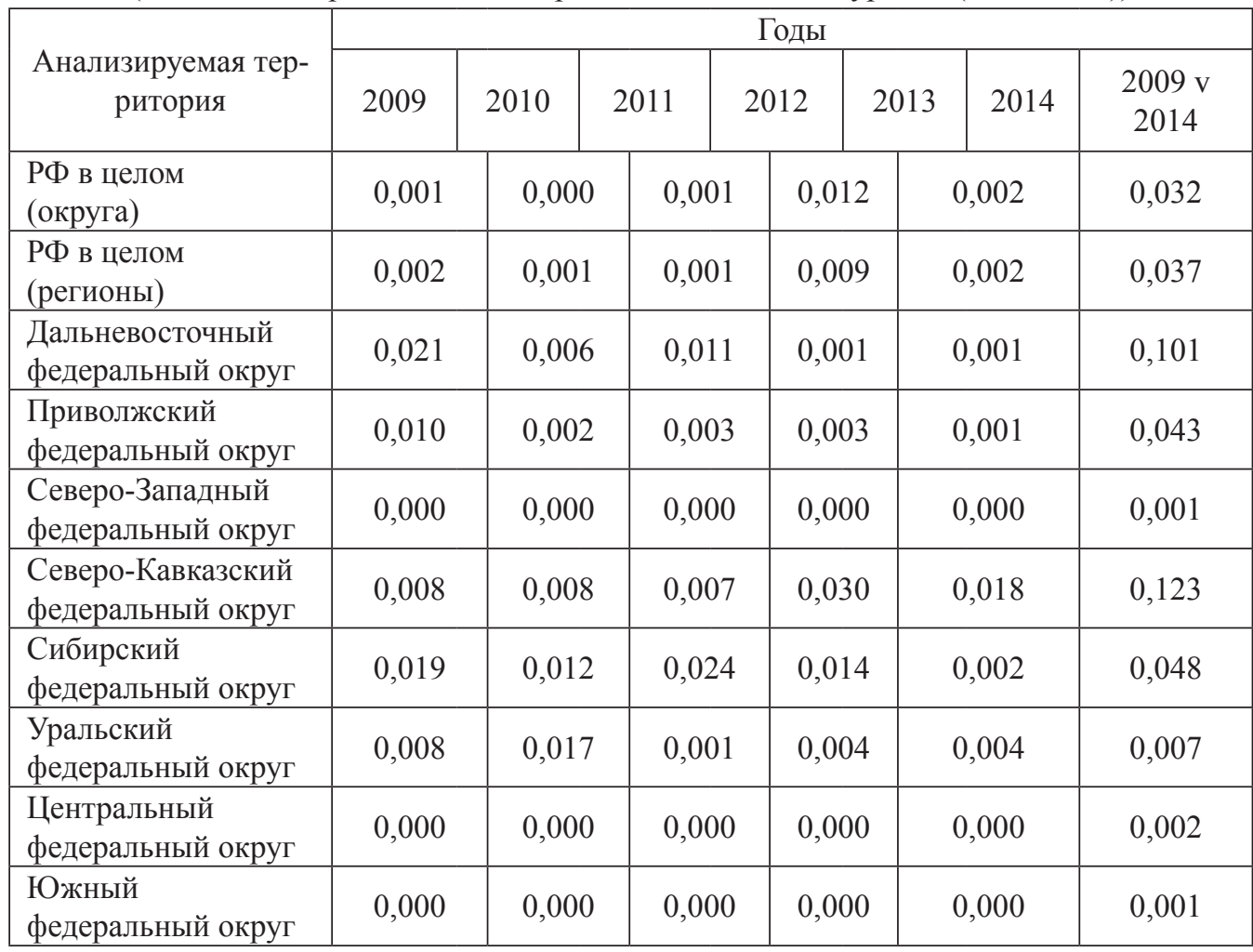


Такие условия должны благоприятствовать реализации новых инициатив, однако лишь в том случае, если конкуренция происходит на фоне общего увеличения параметров этого хозяйства, что, судя по имеющимся данным (табл. 5), имеет место отнюдь не повсеместно.
В-третьих, в отдельные годы и на отдельных территориях имели место более существенные изменения состояния гостиничного хозяйства в пространстве. Это обращает внимание на возможность периодического возникновения некоторой нестабильности, что выступает в качестве небла-

Таблица 5

Наиболее успешные регионы России по развитию гостиничного хозяйства (составлено авторами по данным Ростуризма ${ }^{4}$ )

\begin{tabular}{|c|c|c|c|}
\hline \multirow[t]{2}{*}{ Регион } & \multicolumn{3}{|c|}{$\begin{array}{c}\text { Регионы, в которых значения параметра непре- } \\
\text { рывно росли на протяжении 2009-2014 гг. }\end{array}$} \\
\hline & $\mathrm{TH}$ & $\mathrm{PH}$ & $\mathrm{IH}$ \\
\hline Белгородская область & & & + \\
\hline Воронежская область & & & + \\
\hline Калужская область & + & & + \\
\hline Смоленская область & & & + \\
\hline Тамбовская область & + & & \\
\hline г. Москва & + & & + \\
\hline Республика Карелия & & & + \\
\hline г. Санкт-Петербург & & + & + \\
\hline Ростовская область & & & + \\
\hline Республика Ингушетия & + & & \\
\hline Карачаево-Черкесская Республика & & & + \\
\hline Ставропольский край & + & + & \\
\hline Республика Башкортостан & & & + \\
\hline Республика Татарстан & & & + \\
\hline Удмуртская Республика & + & & \\
\hline Чувашская Республика & & & + \\
\hline Нижегородская область & & & + \\
\hline Свердловская область & & & + \\
\hline $\begin{array}{l}\text { Ямало-Ненецкий автономный } \\
\text { округ }\end{array}$ & & & + \\
\hline Республика Бурятия & & & + \\
\hline Алтайский край & & + & + \\
\hline Забайкальский край & & & + \\
\hline Красноярский край & & & + \\
\hline Омская область & & & + \\
\hline Республика Саха (Якутия) & & & + \\
\hline Приморский край & & + & + \\
\hline Хабаровский край & & & + \\
\hline Амурская область & & & + \\
\hline
\end{tabular}

${ }^{4}$ URL: http://www.russiatourism.ru/content/8/section/81/detail/4124/ (дата обращения: 03.01.2016). 
гоприятной предпосылки для инвестирования в рассматриваемую отрасль.

В-четвертых, динамика числа лиц, размещенных в КСР, и числа мест в КСР характеризуются сравнимо низкими значениями соответствующих показателей. Однако пространственные изменения, касающиеся такого параметра, как объем платных услуг, оказанных КСР, оказываются несколько более интенсивными. Это означает, что результативность деятельности гостиниц и прочих средств размещения испытывает тенденцию к изменению в пространстве с каждым последующим годом, что не зависит ни от изменений туристских потоков, ни от изменений потенциала КСР. Такое положение особенно хорошо видно на примере Северо-Кавказского федерального округа (табл. 2-4). Сделанное заключение может быть интерпретировано как проявление своего рода «турбулентности», что может создать заметные трудности при реализации конкретных инициатив, долгосрочных проектов, государственных программ и т. п. Действительно, массовый ввод в строй КСР в каком-то конкретном регионе и, следовательно, усиление его кажущейся конкурентоспособности вовсе не обязательно приведут к соответствующему росту результативности деятельности в гостиничном секторе, что ставит под сомнение смысл развития в этом регионе туристической инфраструктуры. Хотя если этот смысл на самом деле очевиден (новые рабочие места, новые доходы и т. п.), отмеченная выше «турбулентность» насторожит потенциальных инвесторов на самой начальной стадии.

Наконец, в-пятых, наиболее интенсивная пространственная динамика всех основных параметров развития гостиничного хозяйства отмечается в Сибирском федеральном округе, что устанавливается как при анализе последовательных пар годов, так и долгосрочных изменений
(2009 v 2014). В долгосрочной перспективе она также фиксируется в Приволжском федеральном округе. Сказанное означает, по всей видимости, как более интенсивную конкуренцию регионов в этих двух округах в отношении их гостиничного хозяйства, так и некоторую нестабильность (невысокую, судя по полученным значениям показателей - табл. 2-4) развития последнего по субъектам Федераций. С практической точки зрения, Приволжский федеральный округ выглядит наиболее привлекательными для реализации инициатив, касающихся ввода в строй новых гостиниц, модернизации ранее существовавших и т. п., т. к. среди его регионов сравнительно много успешных (табл. 5), т. е. конкуренция в нем происходит на фоне роста параметров (по крайней мере, в отдельных субъектах Федерации). Напротив, интенсивная пространственная динамика в Сибирском федеральном округе, в составе которого не так много успешных регионов (табл. 5), явилась следствием не только улучшения, но и ухудшения параметров в отдельных субъектах Федерации, что не делает его столь же привлекательным для инвестирования. Важно отметить, что удаленность туристских дестинаций этого округа, дороговизна соответствующих туров, изменчивость погодных условий могли оказать влияние на туристские потоки в его регионы, делая их менее стабильными, что и результировалось в виде сравнительно более интенсивной пространственной динамики.

Полученные результаты также свидетельствуют о достаточно низкой эффективности усилий, которые предпринимались в последние годы для развития туристической инфраструктуры. Если таковые принесли пользу, то только для тех регионов, где состояние гостиничного хозяйства и изначально было вполне удовлетворительным. Создание и продвижение туристического бренда территории - это способ 
повышения ее конкурентоспособности [36-38]. Хотя в России в последнее время данному аспекту становления индустрии туризма и гостеприимства уделяется достаточно внимания, результаты настоящей работы показывают отсутствие значимых прорывов в этом направлении.

\section{Обсуждение результатов}

Результаты настоящей работы позволяют обсудить связь динамики основных показателей развития гостиничного хозяйства в России. Она может быть определена путем использования коэффициента парной корреляции применительно к значениям показателей $D t h, D p h$ и Dih за рассматриваемый период времени (табл. 2-4). Итоги этого анализа оказываются весьма интересными, хотя и неоднозначными (табл. 6).

Прежде всего обратим внимание на тесную связь между Dth и Dph для России в целом. Она означает, что пространственные изменения числа лиц, воспользовавшихся услугами КСР, зависят от числа мест в КСР, что вполне логично. Тем не менее сделать подобный вывод оказывается невозможным ни для одного федерального округа. Это означает, что указанная выше зависимость не столь сильна на самом деле, и на ее проявление на конкретной территории влияют дополнительные факторы. К числу таковых может относиться, например, недостаточная заполняемость номерного фонда в отдельных регионах. Также весьма показательно отсутствие тесной положительной связи между $D t h$ и $D p h$ с одной стороны и Dih - с другой, что указывает на независимость пространственных изменений результативности деятельности гостиничного хозяйства как от его востребованности, так и от потенциала. Объяснение столь странному факту следует искать в возможной связи пространственной динамики объема платных услуг, оказанных КСР, с платежеспособностью населения, ценовой политикой гостиниц и т. д. В практическом

Таблица 6

Связь значений показателей $D t h, D p h$ и $D i h$ по анализируемым территориям (значения коэффициента парной корреляции рассчитаны авторами по данным табл. 2-4)

\begin{tabular}{|l|c|c|c|}
\hline \multicolumn{1}{|c|}{ Анализируемая территория } & $D t h$ v Dph & $D t h$ v Dih & $D p h$ v Dih \\
\hline $\begin{array}{l}\text { РФ в целом } \\
\text { (округа) }\end{array}$ & $+0,92$ & $-0,15$ & $-0,21$ \\
\hline РФ в целом (регионы) & $+0,96$ & $-0,24$ & $-0,19$ \\
\hline $\begin{array}{l}\text { Дальневосточный федераль- } \\
\text { ный округ }\end{array}$ & $-0,42$ & $-0,07$ & $+0,26$ \\
\hline $\begin{array}{l}\text { Приволжский федеральный } \\
\text { округ }\end{array}$ & $-0,37$ & $-0,50$ & $-0,03$ \\
\hline $\begin{array}{l}\text { Северо-Западный федеральный } \\
\text { округ }\end{array}$ & $-0,25$ & 0 & 0 \\
\hline $\begin{array}{l}\text { Северо-Кавказский федераль- } \\
\text { ный округ }\end{array}$ & $-0,16$ & $+0,13$ & $-0,29$ \\
\hline Сибирский федеральный округ & $-0,65$ & $-0,76$ & $+0,11$ \\
\hline Уральский федеральный округ & $-0,52$ & $-0,11$ & $+0,89$ \\
\hline $\begin{array}{l}\text { Центральный федеральный } \\
\text { округ }\end{array}$ & $+0,42$ & 0 & 0 \\
\hline Южный федеральный округ & $-0,38$ & 0 & 0 \\
\hline
\end{tabular}


отношении сказанное означает, что основные параметры развития гостиничного хозяйства изменяются в пространстве России настолько различно, что прогнозировать кумулятивный эффект от реализации новых инициатив в региональном масштабе очень трудно, если вообще возможно. Очевидно, это дополнительная трудность на пути развития в нашей стране индустрии туризма и гостеприимства.

Охарактеризованная в настоящей работе пространственная динамика основных параметров развития гостиничного хозяйства в России может истолковываться в свете действия самых различных региональных факторов. Так, например, установлено, что на состояние этого хозяйства заметное влияние оказывают состояние региональной экономики и протекающие в ней процессы [20]. Хотя дифференциация российских регионов по уровню экономического развития является хорошо известным фактом, исследователи отмечают также то, что она сохраняется и даже усиливается [39-43]. К аналогичному заключению приводят результаты изучения инновационной активности [44]. Следовательно, в той или иной мере слабая пространственная динамика экономической среды вполне может выступать в качестве фактора, благоприятствующего пространственной стабильности гостиничного хозяйства. Другими исследователями внимание обращалось на преференции туристов и, как следствие, их удовлетворенность оказываемыми услугами [19]. Вполне очевидно, что это также может способствовать пространственным различиям гостиничного хозяйства. Однако вряд ли можно ожидать как большого различия преференций туристов в пределах России, так и существенного изменения всего за пять лет. И это еще одна предпосылка слабости пространственной динамики основных параметров гостиничного хозяйства.
В течение последних лет в России состоялись крупные деловые, политические и спортивные мероприятия, которые привлекли большое число посетителей, и, следовательно, их проведение предполагало существенное преобразование и расширение гостиничного хозяйства. Однако это касается таких субъектов Федерации, как г. Москва, г. Санкт-Петербург, Республика Татарстан, Краснодарский край, Приморский край и т. д., которые и без того являются вполне успешными в отношении индустрии туризма и гостеприимства, о чем свидетельствуют данные Ростуризма (табл. 1). Следовательно, значительные изменения в гостиничном хозяйстве отмеченных регионов вряд ли могли повлиять на распределение субъектов Федерации по значению показателя ТН, РН или IH в масштабе страны или какого-либо федерального округа. Результаты настоящего исследования полностью подтверждают такое предположение. Так, проведение зимних Олимпийских игр в Сочи в 2014 г. потребовало фундаментального преобразования гостиничного хозяйства, ввода в строй новых КСР, модернизации части ранее существовавших и т. п. Однако для Южного федерального округа установлены предельно низкие значения показателей Dth, Dph и Dih (табл. 2-4), т. к. все изменения коснулись только региона проведения олимпиады, а именно Краснодарского края. Возникшие при этом предпосылки развития гостиничного хозяйства в соседних регионах не были использованы в той степени, чтобы это было зафиксировано результатами предпринятого в настоящей работе анализа. Тем не менее, чуть повышенная интенсивность отдельных компонентов изученной пространственной динамики в Дальневосточном федеральном округе вполне может оказаться связанной с изменениями в гостиничном хозяйстве в преддверии саммита АТЭС в 2012 г. Аналогичный вывод может быть сделан и в 
отношении Северо-Западного федерального округа, где проведение большого количества мероприятий вкупе с расширением международного аэропорта Пулково соответствует некоторой интенсификации пространственной динамики.

\section{Заключение}

Количественный анализ пространственной динамики трех основных параметров развития гостиничного хозяйства России позволил составить представление о характере изменений, происходивших в этой сфере за последние годы. Основные выводы настоящего исследования следующие. Во-первых, распределение по регионам туристских потоков, номерного фонда, а также объема оказанных КСР платных услуг очень мало менялось в течение 2009-2014 гг., что свидетельствует о недостаточной конкурентоспособности многих регионов. Во-вторых, наибольшей интенсивностью пространственная динамика отличалась в Сибирском федеральном округе, при этом параметры гостиничного хозяйства отдельных регионов этого округа далеко не всегда испытывали рост. В-третьих, установленная слабость динамики является скорее неблагоприятной предпосылкой для развития гостиничного хозяйства в стране, хотя пространственная стабильность состояния этого хозяйства в регионах может благоприятствовать инвестициям в долгосрочные инициативы, проекты. В-четвертых, отдельные параметры обнаруживают достаточно слабую связь друг с другом в отношении их пространственных изменений. В-пятых, проведение крупных мероприятий, потребовавших существенных преобразований гостиничного хозяйства, не привело к существенным изменениям в его пространственной организации в России в целом и отдельных феде- ральных округах по причине локализации в регионах, которые и без того занимали ведущие позиции по состоянию туристической инфраструктуры.

Практическая значимость предпринятого анализа заключается в том, что его результаты позволяют обратить внимание на некоторые особенности, препятствующие повсеместно успешному становлению индустрии туризма и гостеприимства в нашей стране. С учетом сделанных заключений можно утверждать, что государственные программы, в которых уделяется внимание состоянию туристической инфраструктуры в субъектах Федерации, должны предполагать комплекс мер, направленных на увеличение конкурентоспособности регионального гостиничного хозяйства, а также на сбалансированное друг с другом изменение основных параметров его развития в пространстве страны. Возможно, это позволит одновременно повысить и эффективность реализации этих программ, необходимость чего также выявлена [45]. Безусловно, становление внутреннего туризма в России и отдельных его направлений имеет очень хорошие перспективы (например, [46, 47]). Однако успешное решение этой задачи возможно только одновременно с преодолением негативных явлений, о которых говорится в настоящей работе.

Вопросом, требующим последующего изучения, является прослеживание соотношения между пространственным изменениями, с одной стороны, основных параметров развития гостиничного хозяйства России, а с другой - социально-экономических показателей всех субъектов Федерации. Внимания заслуживает также выяснение причин слабой связи величины туристских потоков и результативности деятельности гостиниц и прочих средств размещения. 


\section{Список использованных источников}

1. Багирян В.А. Современное состояние мирового рынка туристических услуг // Вестник Академии знаний. 2013. № 4. C. 47-55.

2. Архипов А.Ю., Елецкий А.Н. Многополярность глобальной экономики // Российский экономический журнал. 2014. № 3. С. 42-53.

3. Машина А.А. Глобализация экономики и ее влияние на развитие туризма // Современные проблемы и пути их решения в науке, производстве и образовании. 2013. № 1. С. 129-133.

4. Латушко Н.А., Свиридов О.Ю. Ресурсные и институциональные предпосылки формирования регионального финансового центра на юге России // Экономические и гуманитарные исследования регионов. 2013. № 1. С. 87-97.

5. Лапочкина В.В. Особенности экономики впечатлений в период конъюнктурных изменений на примере рынка туризма: российский опыт // Сервис в России и за рубежом. 2014. № 9. С. 150-160.

6. Панкрухин А.П. Состояние, перспективы и проблемы российского рынка туристских услуг // Практический маркетинг. 2012. № 9. С. 4-10.

7. Шерешева М.Ю., Полянская Е.Е. Развитие гостиничного бизнеса в регионах России // Финансы и кредит. 2016. № 2. 37-45.

8. Лебедев К.А. Совершенствование механизмов управления развитием туризма в Российской Федерации // Вестник Тверского государственного университета. Серия: экономика и управление. 2015. № 2. С. 72-81.

9. Сурова С.А. Управление изменениями в деятельности многофункциональных туристско-гостиничных комплексов на основе инновацион- ного подхода // Сервис plus. 2011. № 2. С. 73-79.

10. Шогенова Ф.Б. Экономическая эффективность туризма // Вестник Российского университета кооперации. 2010. № 1. C. 83-86.

11. Bresciani S., Thrassou A., Vrontis D. Determinants of performance in the hotel industry - An empirical analysis of Italy // Global Business and Economics Review. 2015. Vol. 17. P. 19-34.

12. Chen C.-M., Lin Y.-C. An analysis on the concentration-advertising relationship in the hospitality industry // Current Issues in Tourism. 2015. Vol. 18. P. 291-298.

13. Kim H., Kim B.-G. Economic impacts of the hotel industry: An input-output analysis // Tourism Review. 2015. Vol. 70. P. 132-149.

14. Parte-Esteban L., Alberca-Oliver P. New insights into dynamic efficiency: The effects of firm factors // International Journal of Contemporary Hospitality Management. 2015. Vol. 27. P. 107-129.

15. Аносова Е.А. Мониторинг турпотоков как инструмент прогнозирования развития туризма в регионе (на материалах Республики Адыгея) // Новые технологии. 2007. № 4. C. 69-73.

16. Макаренко В.С., Григоренко Т.Н. Потенциальные направления развития въездного и внутреннего туризма Ростовской области // Вестник Национальной академии туризма. 2014. № 1. С. 76-78.

17. Нездойминов С.Г. Туристический поток - фактор конкурентоспособности региона // Ars administrandi. 2014. № 3. С. 78-83.

18. Федоров Р.Г. Развитие малых форм гостиничного бизнеса экономкласса как 
способ привлечения туристического потока // Интеллект. Инновации. Инвестиции. 2012. № 4. С. 51-55.

19. Radojevic T., Stanisic N., Stanic N. Ensuring positive feedback: Factors that influence customer satisfaction in the contemporary hospitality industry // Tourism Management. 2015. Vol. 51. P. 13-21.

20. Yang Z., Cai J. Do regional factors matter? Determinants of hotel industry performance in China // Tourism Management. 2016. Vol. 52. P. 242-253.

21. Niewiadomski P. International hotel groups and regional development in Central and Eastern Europe // Tourism Geographies. 2015. Vol. 17. P. 173-191.

22. Silva R. Multimarket contact, differentiation, and prices of chain hotels // Tourism Management. 2015. Vol. 48. P. 305-315.

23. Тютюшева А.Г. Оценка реализации кластерного подхода в программе «Развитие внутреннего и въездного туризма в Российской Федерации (2011-2018)» // Бизнес. Образование. Право. Вестник Волгоградского института бизнеса. 2015. № 3. C. 161-166.

24. Peiro-Signes A., Segarra-Ona M., Miret-Pastor L., Verma R. The Effect of Tourism Clusters on U.S. Hotel Performance // Cornell Hospitality Quarterly. 2015. Vol. 56. P. 155-167.

25. Ермаченко В.Е. Проблемы согласования методологии оценки потребления туристических услуг на внутреннем рынке // Учет и статистика. 2012. № 4. C. 53-60.

26. Киселева И.А., Трамова А.М. Моделирование прогнозирования спроса на рынке туристических услуг // Науковедение. 2013. № 6. С. 42.

27. Тенянская М.Л. Применение методов статистического анализа в изу- чении приоритетных направлений развития курортно-рекреационного и туристического потенциала региона // Экономика и управление: анализ тенденций и перспектив развития. 2014. № 16. С. 64-69.

28. Чхиквадзе Н.А. Анализ динамики основных статистических показателей развития рынка туристских услуг // Сервис в России и за рубежом. 2011. № 3. C. 181-191.

29. Chen M.-H. A quantile regression analysis of tourism market growth effect on the hotel industry // International Journal of Hospitality Management. 2016. Vol. 52. P. 117-120.

30. Falk M., Hagsten E. Modelling growth and revenue for Swedish hotel establishments // International Journal of Hospitality Management. 2015. Vol. 45. P. 59-68.

31. Аксенов А.П., Монастыренко Д.Ю. Развитие автомобильного туризма в России на основе опыта стран Европы и его влияние на экономику страны // Известия Московского государственного технического университета МАМИ. 2012. № 2. С. 18-22.

32. Малафий А.А., Казыдуб А.В. Развитие гостиничной индустрии в Тульской области // Туризм в современном мире. Проблемы и перспективы. Тула: ТулГУ, 2015. С. 80-83.

33. Рубан Д.А. Инновационный менеджмент в туризме: направления и управленческие действия // Вестник УрФУ. Экономика и управление. 2015. T. 14, № 1. C. 114-126.

34. Kendall M.G. Rank correlation methods. London: Griffin, 1970. 202 p.

35. Козинова А.Т. Практикум по эконометрике. Нижний Новгород: Нижегородский университет, 2011. 96 с.

36. Булина А.О. Бренд территории как ключевой факто ее развития // 
Лабиринт. Журнал социально-гуманитарных исследований. 2013. № 5. C. 23-29.

37. Караваева И.В., Гутова С.В. Оценка восприятия имиджа территории // Социогуманитарный вестник. 2012. № 2. C. 28-33.

38. Gallarza M.G., Gil-Saura I., Calderon Garcia H. Destination image: Towards a Conceptual Framework // Annals of Tourism Research. 2002. Vol. 29. P. 56-78.

39. Жуланов Е.Е. Управление социально-экономической асимметрией регионов как фактор экономического роста // Управление большими системами. 2011. № 32. С. 131-154.

40. Писаренко К.В., Полиди А.А. Экономическая оценка уровня дифференциации (неравномерности) социально-экономического развития регионов РФ // Экономика и предпринимательство. 2015. № 4-1. С. 278-292.

41. Попкова Е.Г., Митрахович Т.Н. Диспропорции экономического роста в регионах РФ: проблемы анализа // Современная экономика: проблемы и решения. 2010. № 2. С. 24-36.

42. Розанова Л.И.Инвестиционное неравенство регионов. Теоретическая и прикладная экономика. 2013. № 1. C. 43-63.
43. Чуракова М.М. Теоретико-методические аспекты исследования диспропорций в развитии экономики регионов // Вестник Института дружбы народов Кавказа. Теория экономики и управления народным хозяйством. 2010. № 3. C. 155-161.

44. Рубан Д.А. Пространственная динамика региональной инновационной активности в России: анализ основных трендов // Известия ВУЗов. Серия «Экономика, финансы и управление производством». 2015. № 3. С. 42-47.

45. Григоренко Т.Н., Казьмина Л.Н. Приоритеты в области развития внутреннего и въездного туризма России на современном этапе // Вестник Национальной академии туризма. 2015. № 4. C. 14-16.

46. Гонтарева Е.Ф., Рубан Д.А. Инновационные предпосылки развития делового туризма на юге России // Вестник Таганрогского института управления и экономики. 2015. № 1. С. 32-36.

47. Курочкин В.Н., Кобина Л.А. Организационно- экономические аспекты сервисной деятельности: физкультурно-спортивные услуги, горнолыжный туризм и сервис. Ростов н/Д.: Дониздат, 2015. 151 с. 
Gontareva E.F., master student, Ruban D.A., PhD, candidate of geological-mineralogical sciences, associate professor,

Southern Federal University, Rostov-on-Don, Russia

\section{DEVELOPMENT OF HOTEL INDUSTRY IN RUSSIA: SPATIAL DYNAMICS OF PRINCIPAL PARAMETERS}

The development of inbound tourism and increasing the number of international tourist arrivals is a highly important task for Russia. A well developed infrastructure is required for a successful solution of the task. The situation in the Russian tourism industry and hospitality is well known, but the development of complex models permitting to describe the character of the development of the hotel industry retains its significance. The aim of the present research is the study of the spatial dynamics of the main parameters of the development of the hotel industry in Russia. This work is based on the quantitative analysis of statistical data for 20092014. Three main parameters are examined, namely the number of persons accommodated in the collective accommodation facilities (CAF), the number of places in CAFs and the amount of paid services provided by CAFs. The calculation of indices of the spatial dynamics of these parameters is based on the calculation of the paired correlation coefficient. The results of the calculations show that the spatial dynamics of all main parameters of the development of the hotel industry in Russia is characterized by low intensity. This means the correspondence of the territories by the parameters of this industry has remained almost the same. The dynamics of the number of persons accommodated in CAFs and the number of places in CAFs are characterized by similarly low values of the relevant indices. However, the spatial changes in such a parameter as the amount of paid services provided by CAFs appear to be larger a bit. The relatively high intensity of the spatial dynamics is established for the Siberian Federal District. Further analysis of the results makes it possible to establish weak relationship between the individual parameters. Factors of the spatial dynamics of the main parameters of development of the hotel industry in Russia may be different. More specifically, these include the influence of regional economic processes. Sport tournaments and other big international events that required transformations in the hotel industry did not influence significantly the studied dynamics. Generally, it is concluded that the distribution of the studied parameters by regions changed only a little in 2009-2014, which indicates insufficient competitiveness of many regions as regards their hotel industry.

Key words: collective accommodation facilities; correlation analysis; spatial regularities; regional economy; tourism.

\section{References}

1. Bagirian, V.A. (2013). Sovremennoe sostoianie mirovogo rynka turisticheskikh uslug [Current state of the world tourism market]. Vestnik Akademii znanii [Bulletin of the Academy of Knowledge], No 4, 47-55.

2. Arkhipov, A.Iu., Eletskii, A.N. (2014). Mnogopoliarnost' global'noi ekonomiki [Multipolarity of the global economy]. Rossiiskii ekonomicheskii zhurnal [Russian Economic Journal], No 3, 42-53.

3. Mashina, A.A. (2013). Globalizatsiia ekonomiki $\mathrm{i}$ ee vliianie na razvitie 
turizma [Economic globalization and its influence on the development of tourism]. Sovremennye problemy i puti $i k h$ resheniia $v$ nauke, proizvodstve $i$ obrazovanii [Contemporary problems and possible solutions in science, industry and education], No 1, 129-133

4. Latushko, N.A., Sviridov, O.Iu. (2013). Resursnye i institutsional'nye predposylki formirovaniia regional'nogo finansovogo tsentra na iuge Rossii [Resource and institutional preconditions of formation of regional financial center in the south of Russia]. Ekonomicheskie $i$ gumanitarnye issledovaniia regionov [Economic and humanities research of the regions], No 1, 87-97.

5. Lapochkina, V.V. (2014). Osobennosti ekonomiki vpechatlenii $\mathrm{V}$ period kon"iunkturnykh izmenenii na primere rynka turizma: rossiiskii opyt [Features of the economy of experiences during term changes on the example of tourism market: Russian experience]. Servis v Rossii i za rubezhom [Service in Russia and abroad], No 9, 150-160.

6. Pankrukhin, A.P. (2012). Sostoianie, perspektivy i problemy rossiiskogo rynka turistskikh uslug [The status, prospects and problems of the Russian market of tourist services]. Prakticheskii marketing [Practical Marketing], No 9, 4-10.

7. Sheresheva, M.Iu., Polianskaia, E.E. (2016). Razvitie gostinichnogo biznesa $\mathrm{v}$ regionakh Rossii [Developing the hotel business in Russian regions]. Finansy $i$ kredit [Finance and credit], No 2, 37-45.

8. Lebedev, K.A. (2015). Sovershenstvovanie mekhanizmov upravleniia razvitiem turizma $\mathrm{V}$ Rossiiskoi Federatsii [Improving mechanisms of managing the development of tourism in Russia]. Vestnik Tverskogo gosudarstvennogo universiteta. Seriia: ekonomika i upravlenie [Herald of Tver State University. Series Economics and Management], No 2, 72-81.

9. Surova, S.A. (2011). Upravlenie izmeneniiami $\mathrm{V}$ deiatel'nosti mnogofunktsional'nykh turistskogostinichnykh kompleksov na osnove innovatsionnogo podkhoda [An innovative approach to managing change in operations of a multifunctional tourist accommodation center]. Servis plus, No 2, 73-79.

10. Shogenova, F.B. (2010). Ekonomicheskaia effektivnost' turizma [Economic efficiency of tourism]. Vestnik Rossiiskogo universiteta kooperatsii [Vestnik of the Russian University of Cooperation], No 1, 83-86.

11. Bresciani, S., Thrassou, A., Vrontis, D. (2015). Determinants of performance in the hotel industry - An empirical analysis of Italy. Global Business and Economics Review, Vol. 17, 19-34.

12. Chen, C.-M., Lin, Y.-C. (2015). An analysis on the concentrationadvertising relationship in the hospitality industry. Current Issues in Tourism, Vol. 18, 291-298.

13. Kim, H., Kim, B.-G. (2015). Economic impacts of the hotel industry: An input-output analysis. Tourism Review, Vol. 70, 132-149.

14. Parte-Esteban, L., Alberca-Oliver, P. (2015). New insights into dynamic efficiency: The effects of firm factors. International Journal of Contemporary Hospitality Management, Vol. 27, 107-129.

15. Anosova, E.A. (2007) Monitoring turpotokov kak instrument prognozirovaniia razvitiia turizma $\mathrm{v}$ regione (na materialakh Respubliki 
Adygeia) [Monitoring of tourist flows as a tool for forecasting the development of tourism in a region (the case of the Republic of Adygea]. Novye tekhnologii [New technologies], No 4, 69-73.

16. Makarenko, V.S., Grigorenko, T.N. (2014). Potentsial'nye napravleniia razvitiia v"ezdnogo i vnutrennego turizma Rostovskoi oblasti [Potential directions of inbound and domestic tourism development of the Rostov Region]. Vestnik Natsional'noi akademii turizma [Vestnik of National Tourism Academy], No 1, 76-78.

17. Nezdoiminov, S.G. (2014). Turisticheskii potok - faktor konkurentosposobnosti regiona [Tourist flow as a factor of a region's competitive advantage]. Ars administrandi [Art of management], No 3, 78-83.

18. Fedorov, R.G. (2012). Razvitie malykh form gostinichnogo biznesa ekonomklassa kak sposob privlecheniia turisticheskogo potoka [Development of small budget hotels as a way of attracting tourists]. Intellekt. Innovatsii. Investitsii [Intellect. Innovation. Investment], No 4, 51-55.

19. Radojevic, T., Stanisic, N., Stanic, N. (2015). Ensuring positive feedback: Factors that influence customer satisfaction in the contemporary hospitality industry. Tourism Management, Vol. 51, 13-21.

20. Yang, Z., Cai, J. (2016). Do regional factors matter? Determinants of hotel industry performance in China. Tourism Management, Vol. 52, 242-253.

21. Niewiadomski, P. (2015). International hotel groups and regional development in Central and Eastern Europe. Tourism Geographies, Vol. 17, 173-191.

22. Silva, R. (2015). Multimarket contact, differentiation, and prices of chain hotels. Tourism Management, Vol. 48, 305-315.

23. Tiutiusheva, A.G. (2015). Otsenka realizatsii klasternogo podkhoda $\mathrm{V}$ programme «Razvitie vnutrennego i v"ezdnogo turizma v Rossiiskoi Federatsii (2011-2018)» [Evaluation of implementation of the cluster approach in the program «Development of domestic and inbound tourism in the Russian Federation (2011-2018)»]. Biznes. Obrazovanie. Pravo. Vestnik Volgogradskogo instituta biznesa [Business. Education. Law. Bulletin of Volgograd Business Institute], No 3, 161-166.

24. Peiro-Signes, A., Segarra-Ona, M., Miret-Pastor, L., Verma, R. (2015). The Effect of Tourism Clusters on U.S. Hotel Performance. Cornell Hospitality Quarterly, Vol. 56, 155-167.

25. Ermachenko, V.E. (2012). Problemy soglasovaniia metodologii otsenki potrebleniia turisticheskikh uslug na vnutrennem rynke [Problems of harmonization of evaluation methodology consumption of tourist services in the internal market]. Uchet $i$ statistika [Accounting and statistics], No 4, 53-60.

26. Kiseleva, I.A., Tramova, A.M. (2013). Modelirovanie prognozirovaniia sprosa na rynke turisticheskikh uslug [Modeling demand forecasting in the travel market]. Naukovedenie, No 6, 42.

27. Tenianskaia, M.L. (2014). Primenenie metodov statisticheskogo analiza $\mathrm{v}$ izuchenii prioritetnykh napravlenii razvitiia kurortno-rekreatsionnogo i turisticheskogo potentsiala regiona [Using methods of statistical analysis for studying priority trends in the development of tourist and recreational potential of a region]. Proceedings of international conference "Ekonomika 
$i$ upravlenie: analiz tendentsii $i$ perspektiv razvitiia" [Economics and management: Analysis of trends and prospects of development], No 16, 64-69.

28. Chkhikvadze, N.A. (2011). Analiz dinamiki osnovnykh statisticheskikh pokazatelei razvitiia rynka turistskikh uslug [Analysis of dynamics of key statistical indicators of tourism market development]. Servis v Rossii $i$ za rubezhom [Service in Russia and abroad], No 3, 181-191.

29. Chen, M.-H. (2016). A quantile regression analysis of tourism market growth effect on the hotel industry. International Journal of Hospitality Management, Vol. 52, 117-120.

30. Falk, M., Hagsten, E. (2015). Modelling growth and revenue for Swedish hotel establishments. International Journal of Hospitality Management, Vol. 45, 59-68.

31. Aksenov, A.P., Monastyrenko, D.Iu. (2012). Razvitie avtomobil'nogo turizma v Rossii na osnove opyta stran Evropy i ego vliianie na ekonomiku strany [Development of auto tourism in Russia based on experience of Europe and its impact on the economy of the country]. Izvestiia Moskovskogo gosudarstvennogo tekhnicheskogo universiteta MAMI [Izvestiya MGTU "MAMI"], No 2, 18-22.

32. Malafii, A.A., Kazydub, A.V. (2015). Razvitie gostinichnoi industrii $\mathrm{V}$ Tul'skoi oblasti [Development of the hotel industry in Tula Region]. Proceedings of international conference "Turizm $v$ sovremennom mire. Problemy $i$ perspektivy" [Tourism in modern world. Problems and prospects], 80-83.

33. Ruban, D.A. (2015). Innovatsionnyi menedzhment $\mathrm{v}$ turizme: napravleniia i upravlencheskie deistviia [Innovation management in tourism: directions and managerial actions]. Vestnik UrFU. Seriia ekonomika i upravlenie [Bulletin of UrFU. Series Economics and Management], Vol. 14, No 1, 114-126.

34. Kendall, M.G. (1970). Rank correlation methods. London, Griffin, 202.

35. Kozinova, A.T. (2011). Praktikum po ekonometrike [Exercises in econometrics]. Nizhnii Novgorod University.

36. Bulina, A.O. (2013). Brend territorii kak kliuchevoi faktor ee razvitiia [The brend of a region as a key factor of its development]. Labirint [Labyrinth], No 5, 23-29.

37. Karavaeva, I.V., Gutova, S.V. (2012). Otsenka vospriiatiia imidzha territorii [Assessment of the perception of the image of a territory]. Sotsiogumanitarnyi vestnik [Bulletin of sociology and humanities], No 2, 28-33.

38. Gallarza, M.G., Gil-Saura, I., Calderon Garcia, H. (2002). Destination image: Towards a Conceptual Framework. Annals of Tourism Research, Vol. 29, 56-78.

39. Zhulanov, E.E. (2011). Upravlenie sotsial'no-ekonomicheskoi asimmetriei regionov kak faktor ekonomicheskogo rosta [Managing socio-economic asymmetry of regions as a factor of economic growth]. Upravlenie bol'shimi sistemami [Large scale systems control], No 32, 131-154.

40. Pisarenko, K.V., Polidi, A.A. (2015). Ekonomicheskaia otsenka urovnia differentsiatsii (neravnomernosti) sotsial'no-ekonomicheskogo razvitiia regionov RF [Economic assessment of the level of differentiation (inequality) in social and economic development of Russia's regions]. Ekonomika 
$i$ predprinimatel'stvo [Journal of economy and entrepreneurship], No 4-1, 278-292.

41. Popkova, E.G., Mitrakhovich, T.N. (2010). Disproportsii ekonomicheskogo rosta $\mathrm{V}$ regionakh $\mathrm{RF}$ : problemy analiza [Disproportions of economic growth in regions in the Russian Federation: Problems of the analysis]. Sovremennaia ekonomika: problemy $i$ resheniia [Modern economics: Problems and solutions], No 2, 24-36.

42. Rozanova, L.I. (2013). Investitsionnoe neravenstvo regionov [Investment inequality of regions]. Teoreticheskaia $i$ prikladnaia ekonomika [Theoretical and Applied Economics], No 1, 43-63.

43. Churakova, M.M. (2010). Teoretikometodicheskie aspekty issledovaniia disproportsii $\mathrm{v}$ razvitii ekonomiki regionov [Theoretical and methodological aspects research into regional economic development disproportions]. Vestnik Instituta druzhby narodov Kavkaza. Teoriia ekonomiki $i$ upravleniia narodnym khoziaistvom [Bulletin of Peoples' Friendship Institute of the Caucasus], No 3, 155-161.

44. Ruban, D.A. (2015). Prostranstvennaia dinamika regional'noi innovatsionnoi aktivnosti v Rossii: analiz osnovnykh trendov [Spacial dynamics of regional innovation activity in Russia: Analysis of key trends]. Izvestiia VUZov. Seriia
«Ekonomika, finansy $i$ upravlenie proizvodstvom» [News Of Higher Educational Institutions. A Series «Economy, Finance And Production Management»], No 3, 42-47.

45. Grigorenko, T.N., Kaz'mina, L.N. (2015). Prioritety v oblasti razvitiia vnutrennego i v"ezdnogo turizma Rossii na sovremennom etape [Priorities in domestic and inbound tourism development in Russia at the present stage]. Vestnik Natsional'noi akademii turizma [Vestnik of National Tourism Academy], No 4, 14-16.

46. Gontareva, E.F., Ruban, D.A. (2015). Innovatsionnye predposylki razvitiia delovogo turizma na iuge Rossii [Innovation preconditions for development of business tourism in the south of Russia]. Vestnik Taganrogskogo instituta upravleniia $i$ ekonomiki [Bulletin of the Taganrog Institute of Management and Economics], No 1, 32-36.

47. Kurochkin, V.N., Kobina, L.A. (2015). Organizatsionno-ekonomicheskie aspekty servisnoi deiatel'nosti: fizkul'turno-sportivnye uslugi, gornolyzhnyi turizm $i$ servis [Organizational and economic aspects of service business: sports and fitness services, downhill ski tourism and service]. Rostov na Donu, Donizdat.

\section{Information about the authors}

Gontareva Elena Fedotovna - Master Student, Higher School of Business, Southern Federal University, Rostov-on-Don, Russia (344019, Rostov-on-Don, 23-ja Linija Street, 43); e-mail: lenagontareva@bk.ru.

Ruban Dmitry Aleksandrovitch - Philosophiae Doctor, Candidate of GeologicalMineralogical Sciences, Associate Professor, Department of Tourism, Higher School of Business, Southern Federal University, Rostov-on-Don, Russia (344019, Rostov-on-Don, 23-ja Linija Street, 43); e-mail: ruban-d@mail.ru. 